\title{
Larva Migrans Cutánea: casos pediátricos
}

\author{
Cutaneous larva migrans: pediatric cases
}

Gustavo A. Lizardo Castro, ${ }^{1}$ Aleydi Gómez Campos. ${ }^{2}$

\author{
${ }^{1}$ Médico Pediatra, Sub-especialista en Dermatología, Departamento de Pediatría, Servicio de Dermatología, \\ Hospital Escuela; Universidad Nacional Autónoma de Honduras (UNAH). \\ ${ }^{2}$ Médico Residente Tercer Año, Posgrado de Dermatología, Facultad de Ciencias Médicas UNAH; Tegucigalpa, Honduras.
}
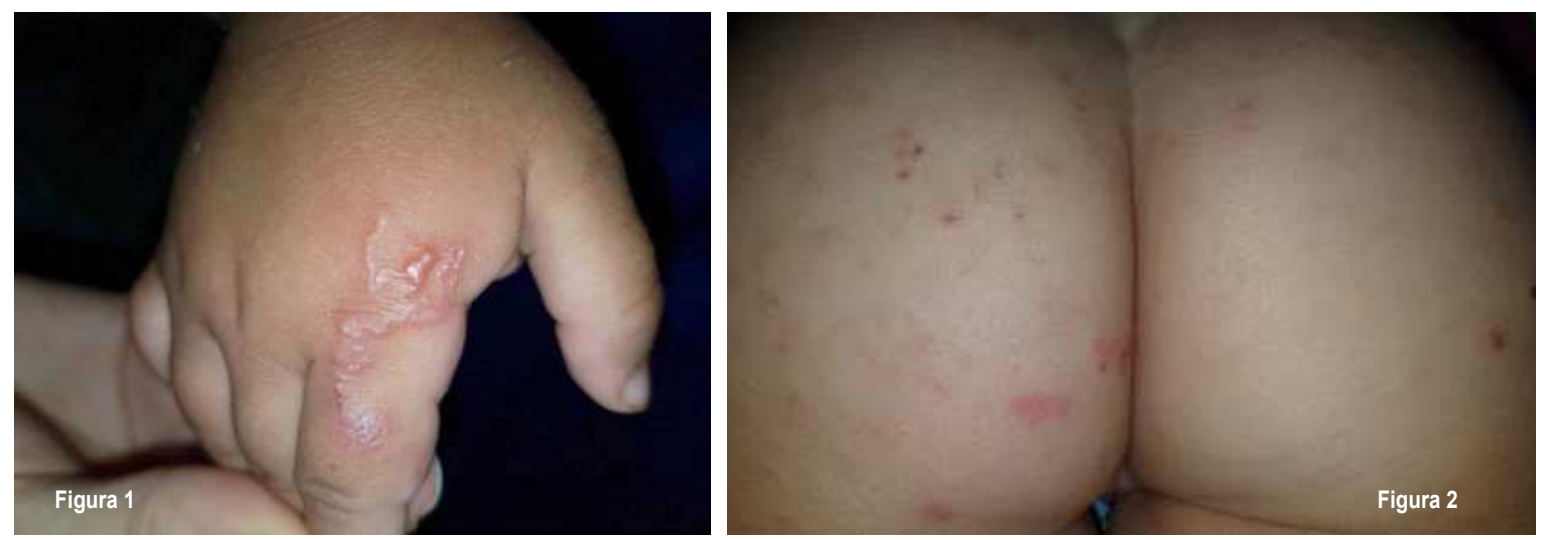

Niña de 2 años de edad, con lesión en dorso de mano derecha con trayecto serpiginoso sobreelevado en base eritematosa, presencia de vesículas, pruriginosas, de 3 semanas de evolución, originada durante un viaje al Caribe hondureño (Figura 1). Se manejó con crioterapia obteniendo resolución del cuadro clínico. La larva migrans cutánea (LMC) es frecuente en climas tropicales y subtropicales, ocasionada por nemátodos del género Ancylostoma spp., principalmente Ancylostoma braziliense, adquirida por contacto con arena contaminada con heces de perros y gatos infectados. El diagnóstico es clínico, caracterizado por erupción serpiginosa, eritematosa y pruriginosa, causada por el avance de la larva dentro de la epidermis. Existen formas atípicas constituidas por pápulas foliculares conocida como LMC folicular (Figura 2, niña de 19 meses con lesiones iniciadas 10 días atrás, después de jugar en la playa). Localización frecuente de la LMC son las extremidades inferiores, manos, nalgas y espalda, siendo su evolución autolimitada por la muerte del parásito entre 1 y 3 meses. Su manejo es eficaz y seguro con una de las siguientes alternativas: crioterapia, albendazol tópico cada 8 horas x 5 dias, albendazol $400 \mathrm{mg}$ VO cada $12 \mathrm{~h} \times 3$ dias o ivermectina $200 \mu \mathrm{gg} /$ $\mathrm{kg}$ VO dosis única.

Recibido: 22-5-2019; Aceptado para publicación 20-6-2019

Dirección para correspondencia: Dr. Gustavo Lizardo

Correo electrónico: glizardoc@yahoo.com

Conflictos de interés. Los autores declaran no poseer ningún conflicto de interés en relación a este artículo. 